\title{
Open reduction and internal fixation of paediatric mandibular fracture: a case report and review of literature
}

\author{
Surya Rao Rao Venkata Mahipathy ${ }^{1 *}$, Alagar Raja Durairaj ${ }^{1}$, James Solomon Jesudasan ${ }^{2}$, \\ Narayanamurthy Sundaramurthy ${ }^{1}$, Manimaran Ramachandran ${ }^{1}$, Praveen Ganesh Natarajan ${ }^{1}$
}

${ }^{1}$ Department of Plastic and Reconstructive Surgery, ${ }^{2}$ Department of Oral Maxillofacial Surgery, Saveetha Medical

College and Hospital, Kanchipuram District, Tamil Nadu, India

Received: 25 July 2018

Revised: 28 August 2018

Accepted: 05 September 2018

\author{
*Correspondence: \\ Dr. Surya Rao Rao Venkata Mahipathy, \\ E-mail: surya_3@hotmail.com
}

Copyright: () the author(s), publisher and licensee Medip Academy. This is an open-access article distributed under the terms of the Creative Commons Attribution Non-Commercial License, which permits unrestricted non-commercial use, distribution, and reproduction in any medium, provided the original work is properly cited.

\begin{abstract}
The type of craniomaxillofacial fractures in children and young adults varies with evolving skeletal anatomy and social and environmental factors. The general principles of treating mandibular fractures are common for children and adults: Anatomic reduction along with rigid skeletal stabilization is mandatory until bone union has occurred. Here we present a female child with a road traffic accident presenting with fractures of the right parasymphysis and the left angle of the mandible with significant displacement. Open reduction and internal fixation with stainless steel miniplates and screws was done, with good post-operative recovery.
\end{abstract}

Keywords: Fixation of paediatric fractures, Paediatric trauma, Paediatric facial fractures

\section{INTRODUCTION}

Compared with adults, fractures of the facial bones and mandible are uncommon in the paediatric age group, particularly those patients younger than 5 years.

The impact of craniofacial trauma is minimized by the reduced inertia, due to the light weight and small size. The force of impact is absorbed by the forehead and the skull rather than the face since the ratio of cranial volume to facial volume is greater in children than adults. Besides, paediatric facial bones are more resistant to fractures due to their higher elasticity, poor pneumatization (by sinuses) and stabilization of the mandible and maxilla by the unerupted teeth. Incidence rates of mandibular fractures in children have been fairly consistent in the literature over the years. In 1956, MacLennan reported that $1 \%$ of mandibular fractures occur in children younger than 6 years. ${ }^{1}$ Similarly, in Rowe's 1969 study, 5\% of mandibular fractures were in children aged 6 to 11 years; only $1 \%$ occurred in patients younger than 5 years. ${ }^{2}$ In several series, motor vehicle accidents and falls were the most common causes of paediatric mandibular fractures.

\section{CASE REPORT}

A 4-year-old girl child reported to the Department of Plastic Surgery along with her parents, with an open mouth appearance and lacerations on the left cheek and left mandibular angle region after a history of road traffic accident.

On examination there was evident malocclusion and a step deformity in relation to the left angle of the mandible with a large extraoral laceration. The girl was unable to 
close her mouth and in considerable pain. A computed tomography $(\mathrm{CT})$ with $3 \mathrm{D}$ reconstruction was done under supervised sedation with the help of the paediatric team. The CT showed a fractured left mandibular angle and right parasymphysis (Figure 1).

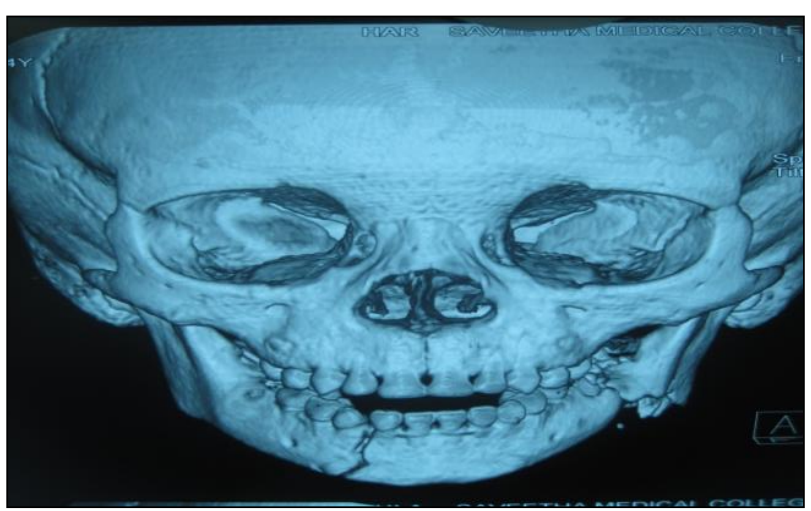

Figure 1: 3D CT scan showing fracture of right parasymphysis and left angle of mandible.

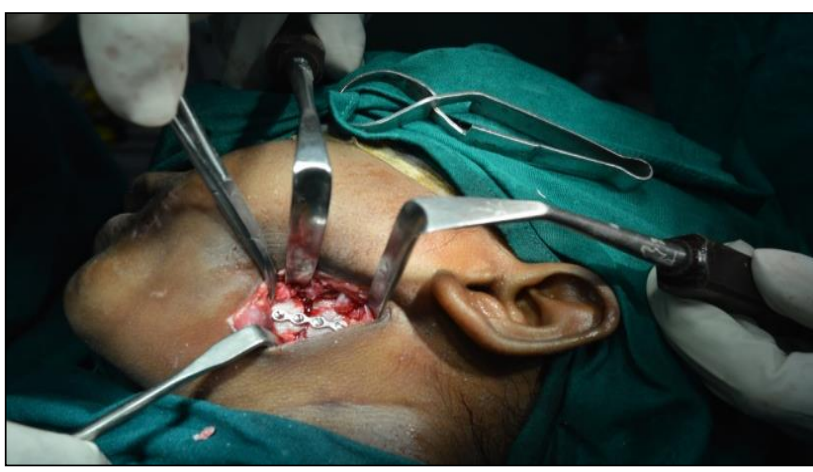

Figure 2: Intra-operative photograph showing the plating of the fracture.

Under general anaesthesia with nasotracheal intubation, the airway was secured. Local anaesthetic was injected into the left angle region along the preexisting laceration and fractured bone was exposed.

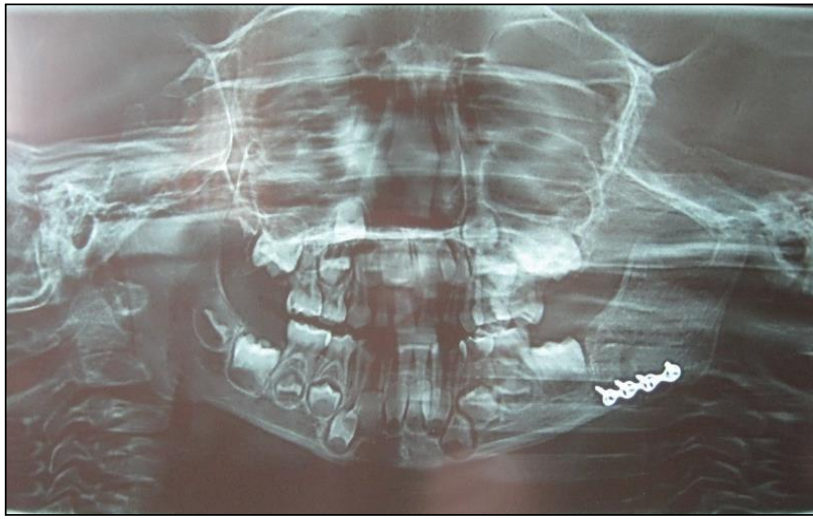

Figure 3: Post-operative OPG showing the miniplate in position.
Care was taken to reduce the fracture and bring the teeth into occlusion. Intra oral occlusion was maintained with the help of a temporary composite bonding on the occlusal surface of the teeth by our pediatric dentist.

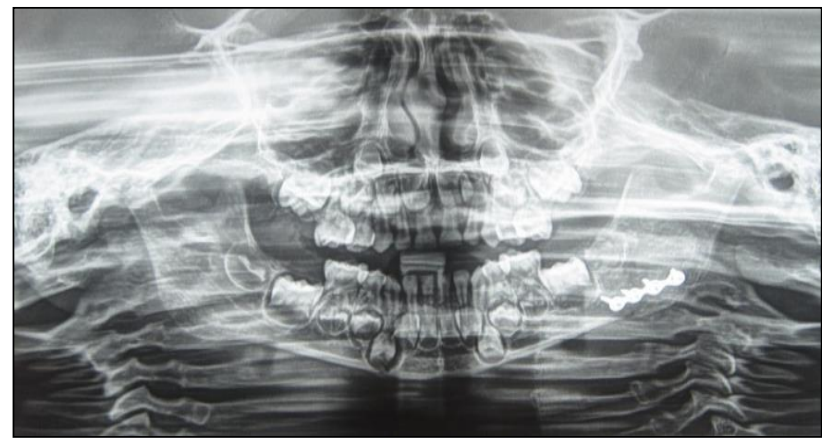

Figure 4: 8 Month follow-up OPG showing good bony union prior to plate removal.

The fractured angle was plated extra orally with a stainless-steel plate and screws taking into concern the tooth buds situated in that region (Figure 2). With the help of the CT images we were able to place the plate below the tooth buds.

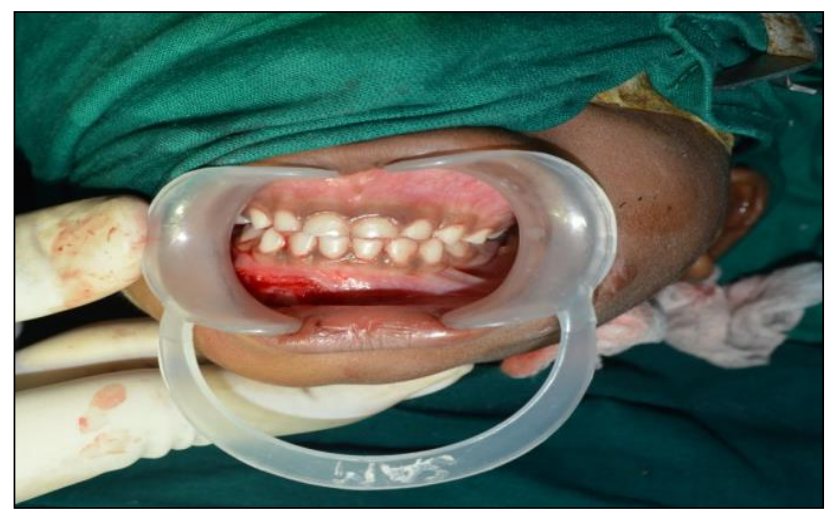

Figure 5: Good occlusion achieved.

Careful closure of the wound was done. Post closure there was no mobility of the segment and no mobility in the Para symphysis region.

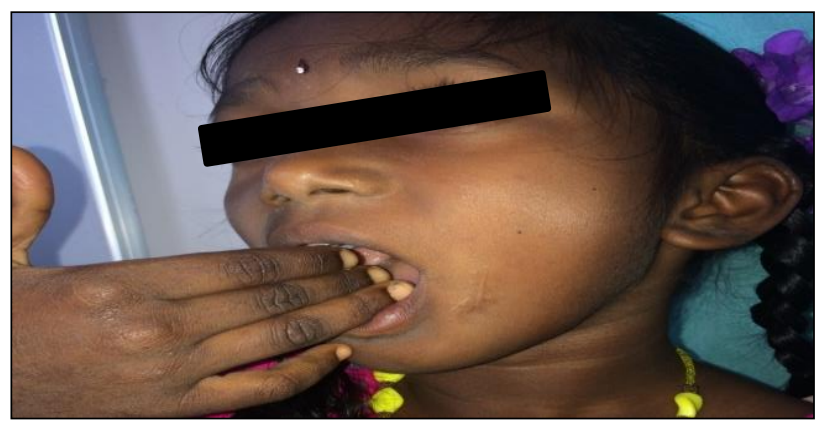

Figure 6: Good mouth opening. 
Post-operative orthopantomography (OPG) confirmed the placement of plate and screws below the tooth buds. (Figure 3). There was a mild deviation of the jaw that was corrected with physiotherapy. The patient was under regular follow up and after a period of 8 months, the plates and screws were removed (Figure 4).

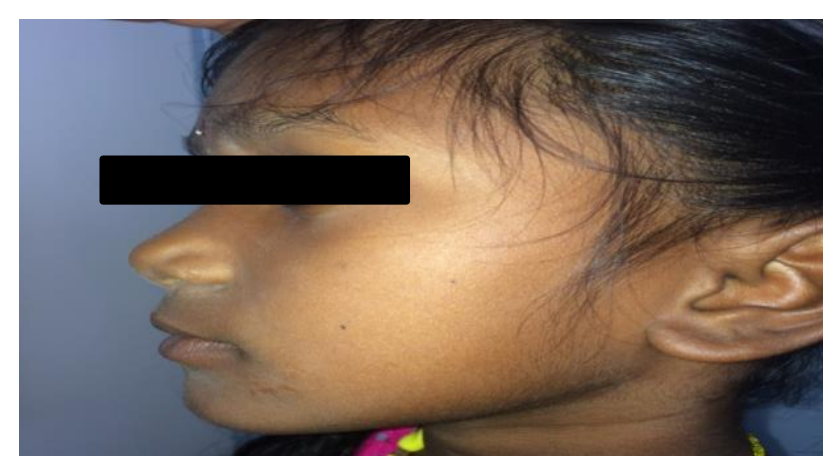

Figure 7: Minimal scar present.

One and a half years post-surgery the patient is doing fine. There was no deviation of the jaw with minimal scar over the laceration and good occlusion (Figure 5). Postoperative CT shows near perfect bone formation and no trace of fractures. There was no trismus in the postoperative period (Figure 6) with minimal scar (Figure 7).

\section{DISCUSSION}

The paediatric mandible fracture is a rare occurrence when compared with the number of mandible fractures that occur within the adult population. Although the clinician who manages facial fractures may never encounter a paediatric mandible fracture, it is a unique injury that warrants a comprehensive discussion.

Because of the unique anatomy, dentition, and growth of the paediatric patient, the management of a paediatric mandible fracture requires true diligence with a variance in treatment ranging from soft diet to open reduction and internal fixation. ${ }^{3}$

Mandibular fractures are the most common facial skeletal injury in pediatric trauma patients. ${ }^{4-6}$ In Posnick and colleagues' study thirty-nine percent of all fractures were of the mandible. The different fracture sites of the mandible included the condyle (59 of 107, 55\%), parasymphysis $(29$ of $107,27 \%)$, body (10 of $107,9 \%$ ) and angle (9 of 107, 8\%). ${ }^{7}$ Bone fragments in the paediatric population may become partially united as early as 4 days and fractures become difficult to reduce by seventh day. ${ }^{8}$

In several series, motor vehicle accidents and falls are the most common causes of paediatric mandibular fractures. However, the frequencies of etiologies of fractures in a Swiss series were $72 \%$ due to recreational activities and $17 \%$ to traffic accidents. Thoren's 1992 series reports
$57 \%$ of fractures were due to vehicular accidents and another $18 \%$ to fall. ${ }^{9}$

During the first years of life, the size and proportions of the facial skeleton change markedly. The facial skeleton increases in relation to the rest of the head, and the sinuses and dentition develop postnatally. The mandible is relatively small at birth and grows by remodeling. The eruption of teeth and the development of the alveolar process also contribute to vertical growth. Apposition of bone at other surfaces causes the bone to develop a more adult shape.

Thus, the mandible assumes a more forward position and a longer shape. The condylar growth centers are crucial in mandibular development. Each center consists of chondrogenic, cartilaginous, and osseous zones. A thin vascular layer covers the chondrogenic zone. Bone is deposited at the posterior borders of the rami and condyles.

Trauma to the growth center just beneath the articular disc is cause for concern. Delayed growth on the affected side can cause facial asymmetry, mandibular deviation, and malocclusion.

The general principles of the management of maxillofacial trauma are similar in both children and adults, but the ongoing developmental changes in the growing face of a child must be taken into consideration. ${ }^{10}$

Adequate treatment of mandibular fractures should accomplish several goals. Restoration of occlusion, function, and facial balance is necessary for therapy to be considered successful. Proper treatment may prevent complications such as growth disturbance and infection. The specific treatment of mandibular fractures depends on location of the fracture, degree of bony displacement, occlusal status, and dentition status of the child. Methods of fixation vary by dental status.

Before age 2 years, the deciduous teeth are not completely erupted. Children at this stage of development are treated as though edentulous. An acrylic splint may be fixed in place with circum-mandibular wires. If immobilization of the jaw is necessary, the splint may be fixed to both occlusive surfaces with both circummandibular wires and wires through the pyriform aperture. ${ }^{11}$

Once deciduous teeth are established, at about ages 2-5 years, they may be used for fixation. Although the deciduous teeth are conically shaped (rather than having a cervical waist), interdental wiring may be used. Arch bars are somewhat more difficult to secure below the gum line. Redundant support may be necessary. Mini-arch bars attached with resin may be used to treat undisplaced fractures, again avoiding immobilization of the mandible. 


\section{CONCLUSION}

The controversy of open treatment versus closed treatment of paediatric mandibular fractures remains. However, recent literature shows a change in using open reduction and internal fixation (ORIF) in paediatric fracture stablilization. The risks of facial growth disturbance in ORIF has not been well supported and the complications and discomforts of putting a young child through splinting or arch bars have not been well documented. Although literature tells us that conservative management is the way to go it clearly fails to shed light on all the short comings of such management.

Funding: No funding sources

Conflict of interest: None declared

Ethical approval: Not required

\section{REFERENCES}

1. MacLennan WD. Fractures of the mandible in children under the age of six years. Br J Plast Surg. 1956;9:125.

2. Rowe NL. Fractures of the jaws in children. J Oral Surg. 1969;27(7):497-507.

3. Goth S, Sawatari Y, Peleg M. Management of pediatric mandible fractures. J Craniofac Surg. 2012;23(1):47-56.

4. Baumann A, Troulis MJ, Kaban LB. Facial trauma II: Dentoalveolar injuries and mandibular fracture. In: Kaban LB, Troulis MJ, editors. Pediatric oral and maxillofacial surgery. Saunders; Philadelphia: 2004:441-61.
5. Dodson TB. Mandibular fractures in children. OMS Knowledge Update Update. 1995;1(II):95-107. Available at http://www.oalib.com/references/14382627

6. Iida S, Matsuya T. Pediatric maxillofacial fractures: their aetiological characters and fracture patterns. J Craniomaxillofac Surg. 2002;30(4):237-41.

7. Posnick JC, Goldstein JA. Surgical management of temporomandibular joint ankylosis in the pediatric population. Plast Reconstr Surg. 1993;91(5):791-8.

8. Kaban LB, Mulliken JB, Murray JE. Facial fractures in children: An analysis of 122 fractures in 109 patients. Plast Reconstr Surg. 1977;59(1):15-20.

9. Thoren H, Iizuka T, Hallikainen D. Different patterns of mandibular fractures in children. An analysis of 220 fractures in 157 patients. J Craniomaxillofac Surg. 1992;20(7):292-6.

10. Siwani R, Tombers NM, Rieck KL, Cofer SA. Comparative analysis of fracture characteristics of the developing mandible: the Mayo Clinic experience. Int $\mathbf{J}$ Pediatr Otorhinolaryngol. 2014;78(7):1066-70.

11. Norholt SE, Krishan V, Sindet-Pedersen S, Jensen I. Pediatric condylar fractures: a long-term follow-up study of 55 patients. J Oral Maxillofac Surg. 1993;51:1302-10.

Cite this article as: Mahipathy SRRV, Durairaj AR, Jesudasan JS, Sundaramurthy N, Ramachandran M, Natarajan PG. Open reduction and internal fixation of paediatric mandibular fracture: a case report and review of literature. Int Surg J 2018;5:3418-21. 